\title{
Clinical diagnosis of prostate cancer using digital rectal examination and prostate-specific antigen tests: a systematic review and meta-analysis of sensitivity and specificity
}

\author{
Nelson C. Okpua ${ }^{1,2^{*}}$ (D), Simon I. Okekpa ${ }^{3,4}$, Stanley Njaka ${ }^{2,5}$ and Augusta N. Emeh ${ }^{2}$
}

\begin{abstract}
Background: Being diagnosed with cancer, irrespective of type initiates a serious psychological concern. The increasing rate of detection of indolent prostate cancers is a source of worry to public health. Digital rectal examination and prostate-specific antigen tests are the commonly used prostate cancer screening tests. Understanding the diagnostic accuracies of these tests may provide clearer pictures of their characteristics and values in prostate cancer diagnosis. This review compared the sensitivities and specificities of digital rectal examination and prostate-specific antigen test in detection of clinically important prostate cancers using studies from wider population.

Main body: We conducted literature search in PubMed, Medline, Science Direct, Wiley Online, CINAHL, Scopus, AJOL and Google Scholar, using key words and Boolean operators. Studies comparing the sensitivity and specificity of digital rectal examination and prostate-specific antigen tests in men 40 years and above, using biopsy as reference standard were retrieved. Data were extracted and analysed using Review manager (RevMan 5.3) statistical software. The overall quality of the studies was good, and heterogeneity was observed across the studies. The result comparatively shows that prostate-specific antigen test has higher sensitivity $(P<0.00001, \mathrm{RR} 0.74, \mathrm{Cl} 0.67-0.83)$ and specificity $(P<0.00001, \mathrm{RR} 1.81, \mathrm{Cl} 1.54-2.12)$ in the detection of prostate cancers than digital rectal examination.

Conclusion: Prostate-specific antigen test has higher sensitivity and specificity in detecting prostate cancers from men of multiple ethnic origins. However, combination of prostate-specific antigen test and standardized digital rectal examination procedure, along with patients history, may improve the accuracy and minimize over-diagnoses of indolent prostate cancers.
\end{abstract}

Keywords: Sensitivity, Specificity, Digital rectal examination (DRE), Prostate-specific antigen test (PSAT), Prostatespecific antigen (PSA)

\section{Background}

Cancers irrespective of the type, are generally perceived as deadly disease [1]. The increasing rate of prostate cancer has become worrisome; as it now constitutes the sixth global leading cause of deaths from malignancies

\footnotetext{
*Correspondence: nelson.okpua@student.usm.my

${ }^{2}$ Department of Nursing Science, Ebonyi State University, P.O. Box 053,

Abakaliki, Nigeria

Full list of author information is available at the end of the article
}

in men [2, 3]. A high proportion of men, especially those within the age of 40 years and above, suffer from prostate cancer (PC), with one out of every seven men at risk of developing PC in his lifetime [4-6]. According to studies, although high proportion of men die from prostate cancer-related complications, about 23 to $66 \%$ of men diagnosed with prostate cancer would never have clinical symptoms $[7,8]$. Further review of autopsies, clinical and epidemiological studies in the USA to evaluate the rate of 
PC over-diagnosis found that 1.7 to $67 \%$ of prostate cancer cases were due to over-diagnosis [8].

Globally, prostate cancer (PC) accounts for $13.3 \%$ out of more than 9.6 million diagnosed cases of cancers [9]. In 2008, PC constituted 899,000 new cases and 258,000 deaths and increased to 1.1 million new cases and 307,000 deaths in 2012 [10-12]. In 2018, over 1.28 million cases of PC were reported with the disease projected to hit 1.7 million new cases and 499,000 deaths by 2030 $[1,3]$.

Report [8] on racial variation shows that prostate cancer predominantly affects black men (248.5 per 100,000 men) compared to white men (156.7 per 100,000). In addition, recent evidence has implicated a genetically transferable risk allele in African ancestry to prostate cancer [13]. However, the incidence per 100,000 population is approximately 50 -fold in developed countries, for instance, 178.8 in USA and 3.9 in India compared to Africa [1]. Studies have suggested that the variation in prostate cancer incidences across regions might be due to over-diagnoses from predominant usage of prostatespecific antigen test [8]. Unfortunately, there are limited studies on contending alternatives to prostate-specific antigen test in diagnosing prostate cancers that may require treatment. Studies that compared the sensitivities and specificities of various prostate cancer screening tests had limited their data to specific ethnic groups. In this review, we hope to compare the benefits of these two widely used prostate cancer screening tools using studies conducted on wider populations.

\section{Main text}

\subsection{Materials and methods}

Information technology has improved access to the numerous best published literature for possible evidencebased decision making in the health sector. According to reports, evidence-based policies are best made using summarised reports from many findings of the contemporary research experts [14].

\subsection{Study design}

This study was underpinned on the checklist for the preferred reporting items for systematic review and metaanalysis (PRISMA) framework. Five major steps guided this study: identifying a clear research question, a systematic search of electronic databases for relevant studies, defining criteria for inclusion and selection of articles, data extraction, and data analysis and reporting of findings. The primary research question that guided this review was "What are the sensitivities and specificities of digital rectal examination and prostate-specific antigen tests in clinical detection of prostate cancers?"

\subsection{Search strategy}

Literature search was systematically conducted on eight databases: PubMed, Medline, Science Direct, Wiley Online, CINAHL, Scopus, AJOL, and Google Scholar using key words and phrases joined by the Boolean operator "AND". The key words used in the search process are: digital rectal examination "AND" prostate cancer; digital rectal examination "AND" prostate cancer "AND" accuracies; digital rectal examination "AND" prostate cancer "AND" sensitivity "AND" specificity. Database filters were used to limit literature hits to peer-reviewed articles published in English language (only), from 1 January 2006 to 31 December 2019. Besides, reference lists of the identified studies were also scrutinized for possible eligible studies.

\subsection{Eligibility criteria}

Two members of our research team (E.A and N.S) independently screened the retrieved studies for eligibility and relevance. The eligibility criteria for inclusion of studies was underpinned in participant, intervention, comparison, and outcome (PICO) framework. Only the studies whose participants were 40 years and above were included. Interventions in the studies were digital rectal examination and prostate-specific antigen tests, and the outcome was positive prostate cancer diagnosis. Only studies that used biopsies as reference standard were include. In addition, only studies published from 2006 to 2019 in English language were included. The study selection flow chart is presented as the PRISMA flow diagram (Fig. 1).

\subsection{Quality appraisal and studies selection}

Two independent researchers (E.A and N.S) also assessed the qualities of all the retrieved studies using the quality assessment tool for diagnostic accuracy studies (QUADAS) and the Standards for Reporting Diagnostic accuracy studies (STARD) adapted for diagnostic studies [15]. These quality assessment tools were combined to ensure accuracy and rigor [15]. The adequacy of sample size, method of recruitment and the use of independent blind assessment in the measurement of outcome were assessed in each study using twelve-items scale (Table 1). Studies with a total score of eight (8) points and above were considered to be of high qualities, while those who scored lesser were considered to have high risks of bias.

\subsection{Data extraction}

Two independent reviewers extracted data from the studies that met the inclusion criteria. Where conflicting opinions were observed, a simple consensus of the research team members were adopted. Domains of 


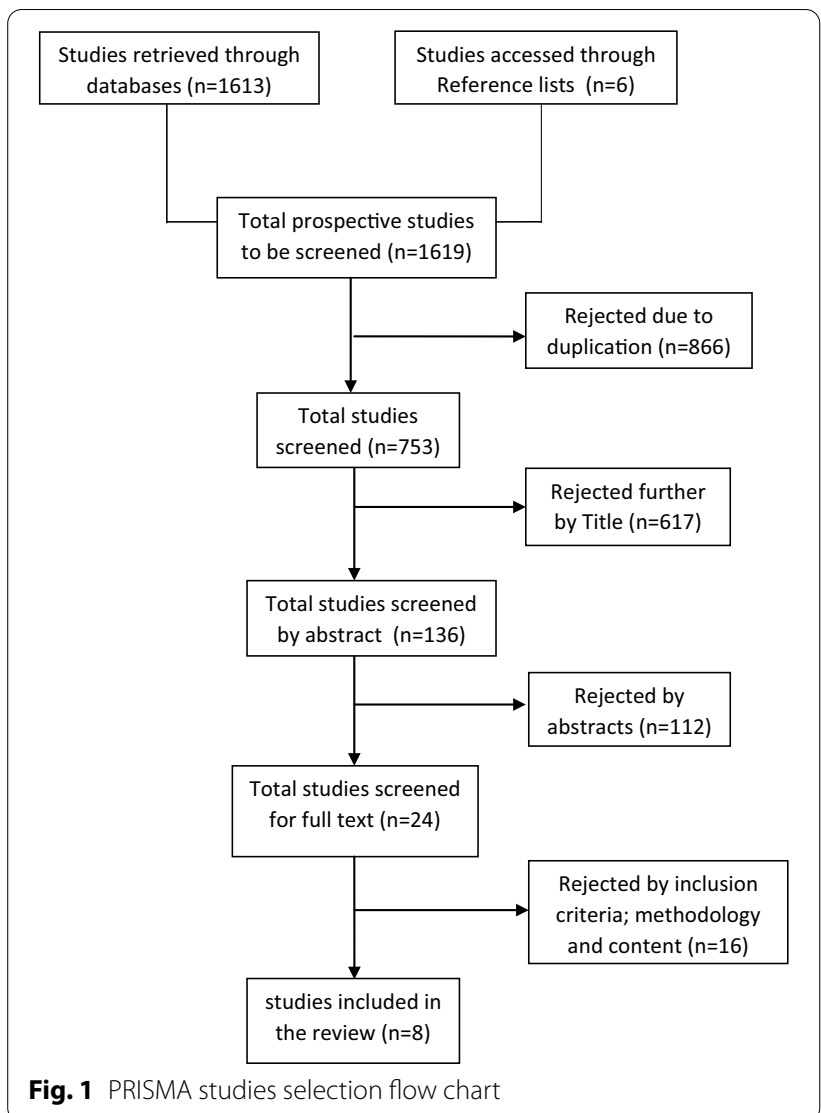

variables extracted from the included studies were: were the last name of the first authors, year of publication, study design, study setting, sample size, intervention or method of data collection, expertise of the experimenters, outcome of the intervention (sensitivities and specificities), and summary of key reported findings (Table 2).

\subsection{Statistical analysis}

Statistical analyses were performed using review manager, RevMan (version 5.3). The specificities and sensitivities were computed against their respective confirmed cases from biopsies. Forest plots for overall sensitivity and specificity of the diagnostic tests (PSAT and DRE) were computed, and the heterogeneity of the included studies were assessed using eye ball tests. Publication bias was estimated using funnel plots, with asymmetrical plots suggestive of possible publication bias [16]. Null hypothesis was theoretically assumed and $P$ value $<0.05$ was taken as indication for any variable to be statistically significant (Figs. 2, 3).

\section{Results}

A total of 1619 studies were identified from the search as potential eligible studies. Majority of these studies were accessed through Google scholar than other databases. However, only eight studies met the inclusion criteria and were included for data extraction and final analysis (Fig. 1).

Table 1 Methodological quality appraisal of included studies using QUADAS AND STARD

\begin{tabular}{|c|c|c|c|c|c|c|c|c|c|c|c|c|c|}
\hline Study & Q1 & Q2 & Q3 & Q4 & Q5 & Q6 & Q7 & Q8 & Q9 & Q10 & Q11 & Q12 & Yes score \\
\hline Walsh et al. [18] & Y & Y & Y & Y & Y & Y & $\mathrm{N}$ & Y & U & Y & Y & Y & 10 \\
\hline De et al. [20] & $U$ & Y & Y & Y & Y & Y & N & Y & $N$ & N & Y & Y & 8 \\
\hline Ojewola et al. [21] & Y & Y & Y & Y & Y & Y & $U$ & Y & $U$ & $N$ & $N$ & Y & 8 \\
\hline Al-Rumaihi et al. [29] & Y & Y & Y & Y & Y & Y & $N$ & Y & $N$ & N & $N$ & Y & 8 \\
\hline Abdrabo et al. [31] & Y & Y & Y & Y & Y & Y & $U$ & Y & $U$ & $\mathrm{~N}$ & Y & Y & 8 \\
\hline Ahmed et al. [17] & Y & Y & Y & Y & Y & Y & $U$ & Y & $U$ & $U$ & Y & Y & 9 \\
\hline Alonso-Sandoica et al. [7] & Y & Y & Y & Y & Y & Y & $\mathrm{N}$ & Y & $U$ & $U$ & Y & Y & 9 \\
\hline Issa et al. [19] & Y & Y & Y & Y & Y & Y & U & Y & U & $\mathrm{N}$ & $\mathrm{N}$ & Y & 8 \\
\hline
\end{tabular}

$Y$ yes, U unclear, NA not applicable, QUADAS Quality Assessment for Diagnostic Accuracy Studies, STARD Standards for Reporting of Diagnostic Accuracy Studies Q1. Were the spectrum of participants a representative of the patients who will receive the test in practice?

Q2. Were selection criteria clearly described?

Q3. Is the time period between reference standard (biopsies) and index test (DRE) short enough to be reasonably sure that the target condition did not change between the two tests?

Q4. Did the whole sample or a random selection of the sample receive verification using a reference standard of diagnosis?

Q5. Did patients receive the same reference standard regardless of the index test result?

Q6. Was the execution of the index test described in sufficient detail to permit replication of the test?

Q7.Were the index test results interpreted without knowledge of the results of the reference standard?

Q8. Were the reference standard results interpreted without knowledge of the results of the index test?

Q9 Were the same clinical data available when test results were interpreted as would be available when the test is used in practice?

Q10. Were un-interpretable/intermediate test results reported?

Q11.Were Sensitivity and specificity results presented with their respective confidence intervals?

Q12. Were the demographic characteristics of participants described? 


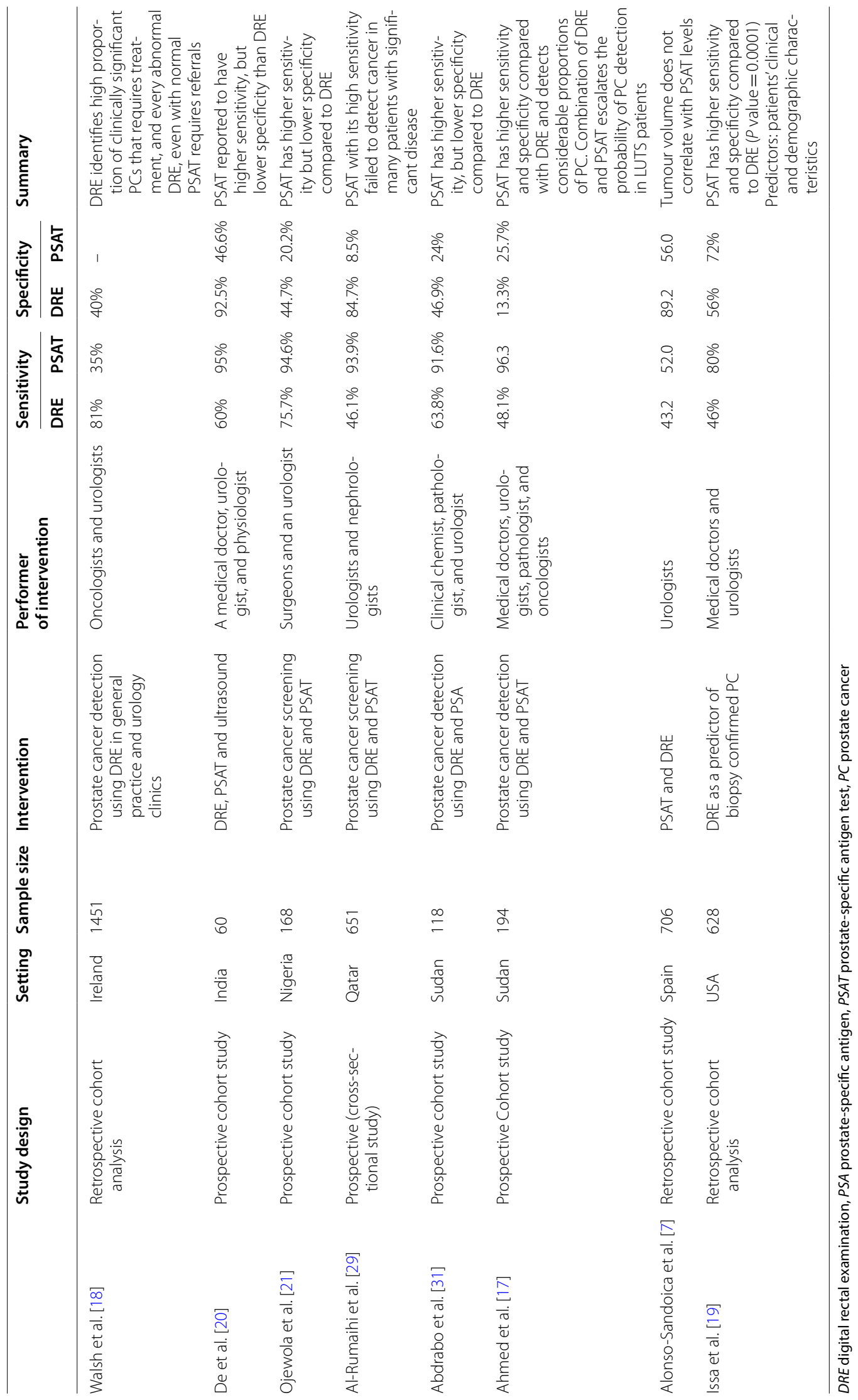


Table 3 Detection accuracy of prostate cancer using DRE and PSAT

\begin{tabular}{|c|c|c|c|c|c|c|c|c|c|c|c|}
\hline \multirow[t]{2}{*}{ Studies } & \multirow[t]{2}{*}{ Sample size } & \multicolumn{2}{|c|}{ Sensitivity (\%) } & \multicolumn{2}{|c|}{ Specificity (\%) } & \multicolumn{2}{|c|}{$\begin{array}{l}\text { Population } \\
\text { with suspicious } \\
\text { test results }\end{array}$} & \multicolumn{2}{|c|}{$\begin{array}{l}\text { Confirmed PC } \\
\text { cases after biopsy }\end{array}$} & \multicolumn{2}{|c|}{$\begin{array}{l}\text { False-positive } \\
\text { cases of PC }\end{array}$} \\
\hline & & DRE & PSAT & DRE & PSAT & DRE & PSAT & DRE & PSAT & DRE & PSAT \\
\hline Sunanda et al. [20] & 60 & 60.0 & 95.0 & 92.5 & 46.6 & 15 & 60 & 9 & 20 & 6 & 40 \\
\hline Walsh et al. [18] & 1451 & 81.0 & 35.0 & 40.0 & 36.0 & 74 & 1348 & 36 & 69 & 38 & 1279 \\
\hline Ojewola et al. [21] & 168 & 75.7 & 94.6 & 44.7 & 20.2 & 108 & 145 & 56 & 74 & 52 & 71 \\
\hline Al-Rumaihi et al. [29] & 651 & 46.1 & 93.9 & 84.7 & 8.5 & 155 & 615 & 83 & 360 & 72 & 255 \\
\hline Abdrado et al. [31] & 118 & 63.8 & 91.6 & 46.9 & 24.0 & 49 & 118 & 23 & 36 & 16 & 82 \\
\hline Ahmed et al. [17] & 194 & 48.1 & 96.3 & 13.3 & 25.7 & 66 & 148 & 26 & 54 & 40 & 94 \\
\hline Alonso-Sandoica et al. [7] & 706 & 43.2 & 52.0 & 89.2 & 56.0 & 141 & 706 & 86 & 199 & 55 & 507 \\
\hline \multirow[t]{2}{*}{ Issa et al. [19] } & 628 & 46.0 & 80.0 & 56.0 & 72.0 & 281 & 604 & 134 & 293 & 147 & 311 \\
\hline & 3976 & & & & & 862 & 3744 & 453 & 1105 & 426 & 2639 \\
\hline
\end{tabular}

Numbers in bold provide comparative figures for false positive cases of PC (over-diagnoses) between PSAT and DRE

$D R E$ digital rectal examination, PSAT prostate-specific antigen test, $P C$ prostate cancer

A total of 3976 men participated in the eight studies analysed, all of whom were 40 years and above. The studies were conducted in seven different countries: Nigeria, Spain, USA, Qatar, Ireland, India and two studies in Sudan. At least one researcher in each of the studies was a Urologist, and three studies (36\%) reported that digital rectal examination was performed by experts [3, $17,18]$. The characteristics of included studies are shown in Table 2.

Result shows that PSAT has both higher sensitivity $(P<0.00001)$ at $95 \%(\mathrm{CI} 0.67-0.83$, risk ratio 0.74$)$ and specificity $(P<0.00001)$ at $95 \%(\mathrm{CI} 1.54-2.12$, risk ratio

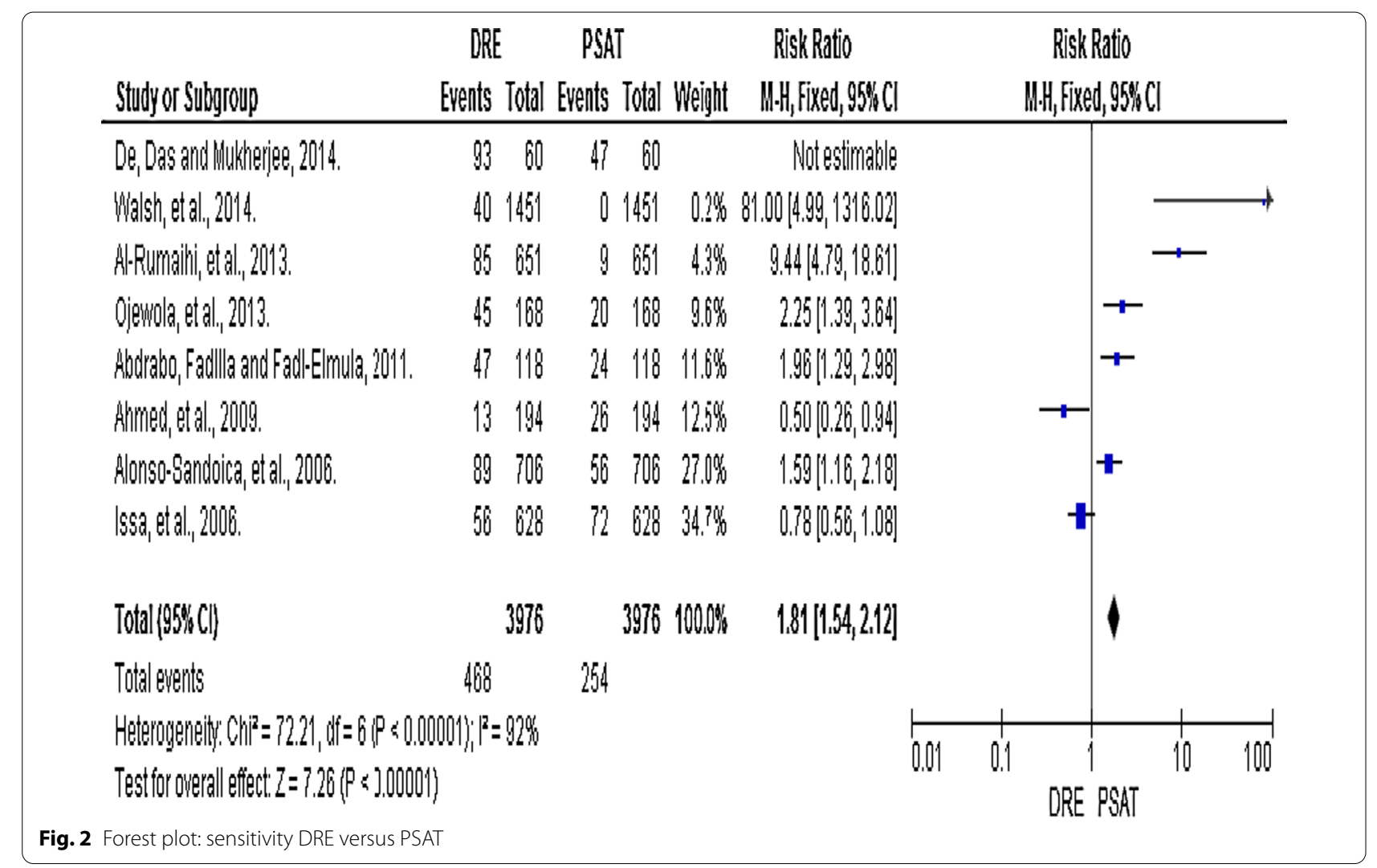


$\begin{array}{lll}\text { DRE } & \text { PSA } & \text { Risk Ratio }\end{array}$

Study or Subgroup

Events Total Events Total Weight M-H, Fixed, 95\% Cl

M.H $\mathrm{H}, \mathrm{Fixed}, 95 \% \mathrm{Cl}$

De, Das and Mukherieg, 2014.

$\begin{array}{llll}60 & 60 & 95 & 60\end{array}$

811451

351451

Notestimable

Wal|sh, etâl, 2014.

Alonso-Sandoica, etal, 2006.

43706

$52706 \quad 9.6 \%$

$2.31[1.57,3.42]$

$195 a$, etal, 2006 .

$46 \quad 628$

$80 \quad 628 \quad 14.7 \%$

$0.83[0.56,1.22]$

Abudrabo, Fadllla and Fad.l-Elmula, 2011.

64118

$92 \quad 118 \quad 16.9 \%$

$0.57[0.41,0.81]$

A. -Rumalihi, et al, 2013.

$46 \quad 651$

$94 \quad 651 \quad 17.3 \%$

$0.70[0.57,0.84]$

Ojewola, etal., 2013.

$76 \quad 168$

$95 \quad 168 \quad 17.5 \%$

$0.49[0.35,0.68]$

Ahmed, et al, 2009 .

$48 \quad 194$

$96 \quad 194 \quad 17.6 \%$

$0.80[0.65,0.099$

$0.50[0.38,0.66]$

Total (95\%) Cl)

3976

$3976100.0 \% \quad 0.74[0.67,0.83]$

Total events

464

639

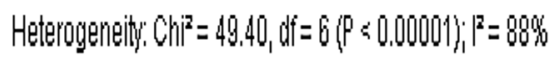

Test tor overall effect: $Z=5.35$ (P < 0.00001$)$

Fig. 3 Forest plot: specificity DRE versus PSAT

1.81) compared to DRE in the detection of true prostate cancers (Figs. 2, 3). Chi-square test showed that the studies were heterogeneous, with $\mathrm{I}^{2}$ of $88 \%$ for sensitivity and $92 \%$ for specificity, respectively. Eye ball test of Funnel plots showed a range of publication bias, suggesting that the studies analysed may not have been the true representative of valid studies undertaken or published on DRE and PSAT (Figs. 4, 5).

\section{Discussion}

Out of the 3976 overall participants in the studies analysed, $862(22 \%)$ had suspicious digital rectal examination (DRE) results while 3744 (94\%) had elevated prostate-specific antigen test (PSAT) results. However, 453 (52\%) of population with abnormal DRE results compared to 1105 (30\%) of sample with elevated PSAT were confirmed through biopsies to have prostate cancer

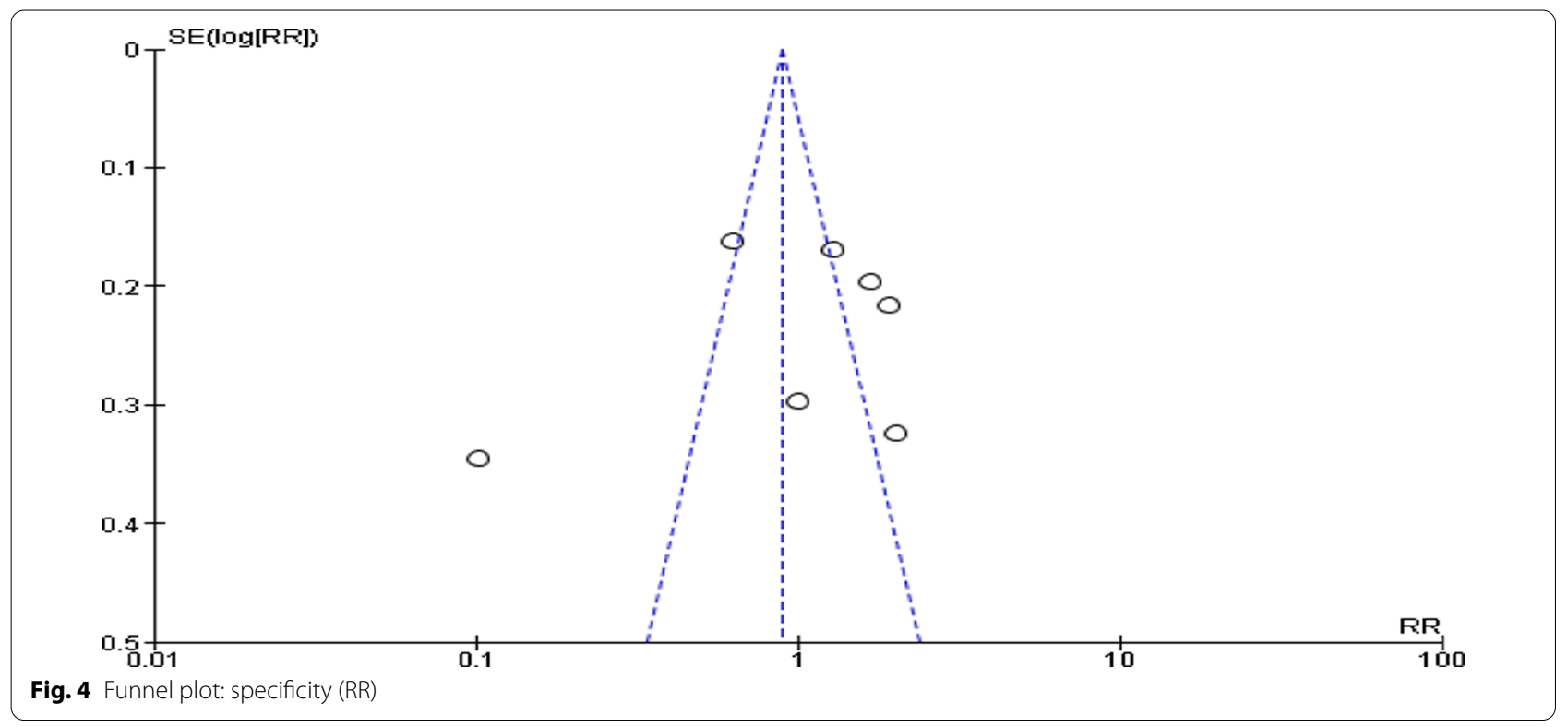




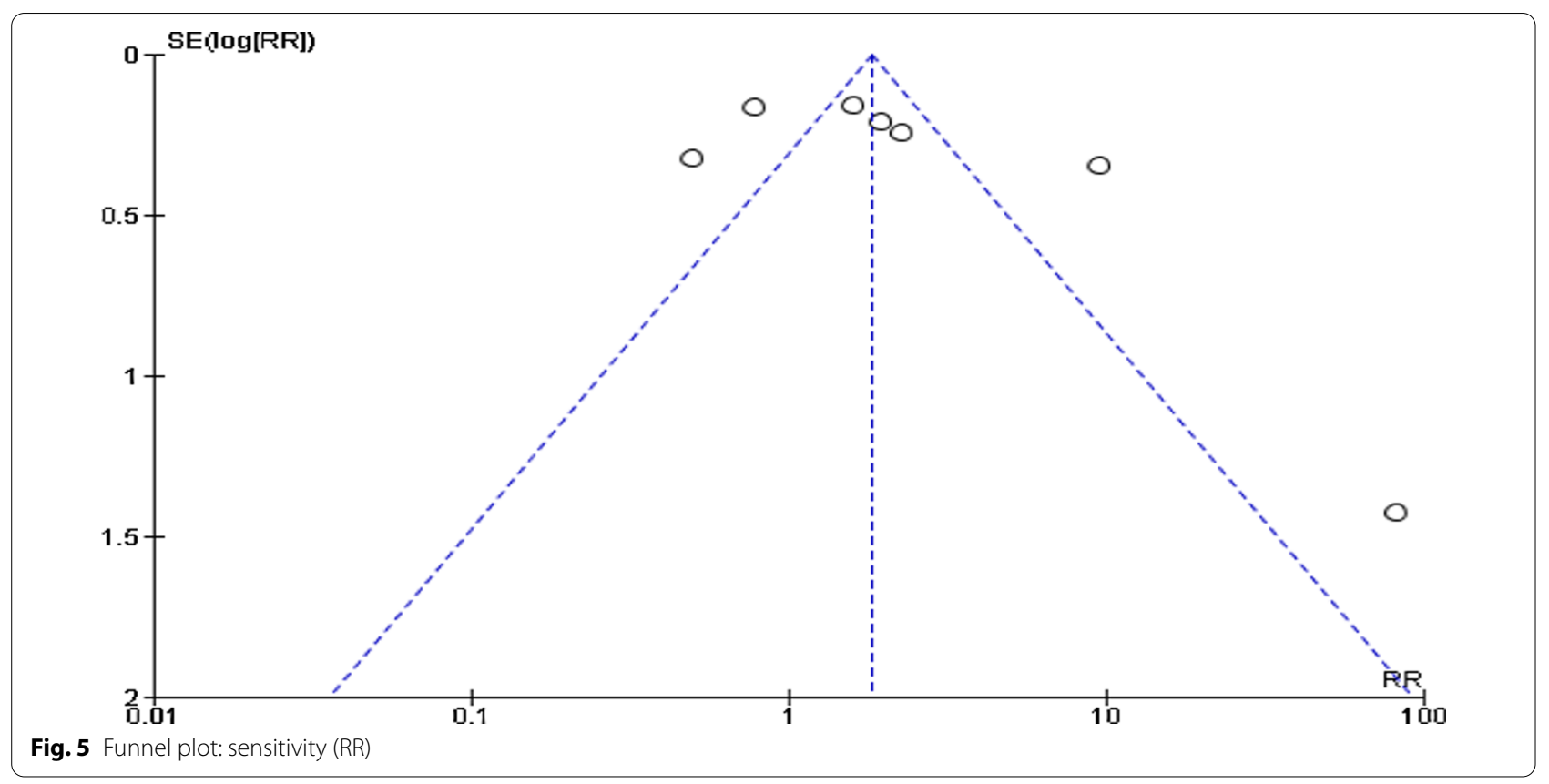

(Table 3$)$. This suggests that as high as 2639 (70\%) against 426 (48\%) of population with abnormal PSAT and DRE results, respectively, were false-positives. This finding is similar to earlier study reports [8], that up to $67 \%$ of prostate cancer (PC) cases are due to over-diagnoses in individuals who will never develop clinical symptoms of PC throughout lifetime.

While there are likelihood for human errors during screening tests, studies have shown that the sensitivity of prostate-specific antigen tests (PSAT) are dependent on pre-set threshold and may be higher for general prostatic diseases [19]. For instance, in two of the studies analysed $[20,21]$, out of 651 and 168 participants with abnormal PSAT results, only $17.6 \%$ and $44 \%$ had prostate cancer, while $56 \%$ and $42.2 \%$ respectively were cases of benign prostate hypertrophy (BPH). On the other hand, DRE has also been reported as non-cancer specific. This is because of its ability to detect all forms advanced tumours of various types and aetiologies. Beside this, inter-observers variability has been consistently reported in DRE screening [22]. This may be due to the differences in expertise, length of observers' index finger and patients' positioning and compliance during the procedure.

Also, this study also found that PSAT has higher sensitivity and specificity (RR 1.81, CI 1.54-2.12) compared to DRE (RR 0.74; CI 0.67-0.83). However, it is important to observe that the sensitivities between PSAT and DRE in this study are within close margin compared to their specificities, suggesting the usefulness of both tools as PC screening tools. The overall effects of sensitivity and specificity in the studies analysed was statistically significant
$(P<0.00001)$; an evidence that the differences in the sensitivities and specificities between DRE and PSAT in the studies analysed may have not occurred by chance. Earlier meta-analyses that compared these prostate cancer screening tools reported that DRE was more sensitive to abnormal growths, especially in detecting advanced tumours requiring treatment $[23,24]$. This report further supports the marginal closeness of the specificities of both tools in this study.

Similarly, a meta-analysis of thirteen studies conducted on participants from the same ethnic group reported a pooled sensitivity and specificity for PSAT as $(72.1 \%$ and 93.2\%) compared to DRE (53.2\% and 83.6\%), respectively [24]. Although there are slight variation with the finding of this study, this may be due to the wide difference between the studies and sample sizes used in the two meta-analyses. Nevertheless, a more recent meta-analysis that evaluated the diagnostic values of PSAT, DRE and Trans-rectal ultrasound (TRUS) among Caucasians using 13 randomised control trials also reported higher sensitivity of PSAT (91.3\%) compared to DRE (68.4\%) compared to this study [25]. These suggest that PSAT may be more specific in a wide range of ethnic population.

Beside these, arguments on what value constitute the best benchmark for diagnosing PC using PSAT has remained a controversial one [26]. While most medical institutions currently use $4.0 \mathrm{ng} / \mathrm{ml}$ as cut-off value for PSAT, researchers have suggested that increasing this value to $5.2 \mathrm{ng} / \mathrm{ml}$ may be a head-way towards reducing the rate of over-diagnosis of indolent PCs, while reducing the cut-off value of PSAT to $3.0 \mathrm{ng} / \mathrm{ml}$ would promote 
potential under-diagnosis $[20,26]$. On the other hand, experts have argued that the fact that DRE were not conducted by a single expert, there is a potential for the inter-examiners variability on the results [27]. Evidence show that examiners' skill, patients' positioning during DRE, anal tone and the nature, including the length of examiners' index fingers, are the factors behind the variation seen across different DRE results [28].

While these important points need not to be overruled, studies conducted in Sudan [29] and USA [30] revealed that combining patients' health histories, clinical and demographic characteristics with $\mathrm{PC}$ screening tools may enhance their diagnostic performances. Similarly, reports [3] show that about $42 \%$ of individuals with cancers have been confirmed to have familial history, suggesting the importance of combining clinical assessments with patients information in PC diagnosis. Therefore, the inclusion of individuals' ethnicity, family and health histories as part of complete PC screening may be useful in assessing high-risk individuals and making more diagnoses of clinically important PCs that require treatment.

\section{Limitations}

A number of limitations needs to be considered while interpreting the result of this study. First, the difficulty in locating all relevant studies using conventional search strategies is a well-established challenge. Although we employed a broad and purposeful search protocol, including full text review of 69 journal articles, unpublished dissertations and abstracts from conferences, the possibility of having omitted relevant studies cannot be over-ruled with ease. Secondly, some of the cohort studies included used small sample sizes less than 61 subjects, with most not reporting their results in confidence intervals. Studies with higher population may provide a stronger evidence.

\section{Conclusion}

Prostate-specific antigen tests have higher sensitivity and specificity in detecting prostate cancers from men of multiple ethnic origins. Combination of PSAT and standardized DRE procedure, along with patients history, may improve the accuracy and minimize over-diagnoses of indolent prostate cancers.

\section{Abbreviations}

PC: prostate cancer; PSAT: prostate-specific antigen test; PSA: prostate-specific antigen; DRE: digital rectal examination.

\section{Acknowledgements}

Authors are thankful to Okpua-Nelson Juliana Chinasa for her inputs on the initial version of manuscript.

\section{Authors' contributions}

All authors contributed significantly to this paper and met the authorship criteria. The conception, design of the research and draft of the initial manuscript were done by NCO. Data collection through independent literature search of databases, quality appraisal of retrieved studies, studies selection and data extraction were done by SN and ANE. Meta-analysis was using RevMan (version 5.3) statistical software was performed by NCO. Extensive manuscript proof-reading and editing was done by SO. All authors read and approved the final manuscript.

\section{Funding}

No funding

\section{Availability of data and materials}

Data and materials are available with considerable requested.

\section{Ethical approval and consent to participate}

Not applicable.

\section{Consent for publication}

Not available.

\section{Competing interests}

There is no competing interests among authors.

\section{Author details}

${ }^{1}$ Cluster of Lifestyle Science, Advanced Medical and Dental Institute (IPPT), Sains@Bertam, Universiti Sains Malaysia, 13200 Kepala Betas, Pinang, Malaysia. ${ }^{2}$ Department of Nursing Science, Ebonyi State University, P.O. Box 053, Abakaliki, Nigeria. ${ }^{3}$ Oncology/Molecular Pathology Cluster, Universiti Sains Malaysia, 11800 Putra Bertam, Pinang, Malaysia. ${ }^{4}$ Department of Medical Laboratory Science, Ebonyi State University, P.O. Box 053, Abakaliki, Nigeria. ${ }^{5}$ Nursing Science Cluster, Universiti Sains Malaysia, Kelantan, Malaysia.

Received: 1 December 2020 Accepted: 1 February 2021

Published online: 17 February 2021

\section{References}

1. Jemal A, Center MM, DeSantis C, Ward EM (2010) Global patterns of cancer incidence and mortality rates and trends. Cancer Epidemiol Prev Biomark 19(8):1893-1907

2. Verma M, Patel P, Verma M (2011) Biomarkers in prostate cancer epidemiology. Cancers 3(4):3773-3798

3. Vickers AJ, Sjoberg DD, Ulmert D, Vertosick E, Roobol MJ, Thompson I, Heijnsdijk EA, De Koning H, Atoria-Swartz C, Scardino PT, Lilja H (2014) Empirical estimates of prostate cancer overdiagnosis by age and prostate-specific antigen. BMC Med 12(1):26

4. Qaseem A, Barry MJ, Denberg TD, Owens DK, Shekelle P (2013) Screening for prostate cancer: a guidance statement from the Clinical Guidelines Committee of the American College of Physicians. Ann Intern Med 158(10):761-769

5. National Health Scheme (2018) Overview: prostate cancer. National Health Scheme-UK. https://www.nhs.uk/conditions/prostate-cancer/. Accessed 17 Nov 2020

6. Siegel RL, Miller KD, Jemal A (2015) Cancer statistics, 2015. CA Cancer J Clin 65(1):5

7. Alonso-Sandoica E, Jara-Rascón J, Martínez-Salamanca Jl, HernándezFernández C (2006) Validezdiagnósticadeltacto rectal en la era de antígenoespecífico de la próstata. Atención Primaria 37(1):9-14

8. Draisma G, Etzioni R, Tsodikov A, Mariotto A, Wever E, Gulati R (2008) Lead time and over diagnosis in prostate specific antigen screening: importance of methods and context. J Natl Cancer Inst 101(6):374-383

9. World Health Organization (2018) Cancer: key facts. World Health Organization. https://www.who.int/news-room/fact-sheets/detail/cancer. Accessed 1 Dec 2020

10. Wolf AM, Wender RC, Etzioni RB, Thompson IM, D'Amico AV, Volk RJ, Brooks DD, Dash C, Guessous I, Andrews K, DeSantis C (2010) American Cancer Society guideline for the early detection of prostate cancer: update 2010. CA Cancer J Clin 60(2):70-98 
11. Zhang A, Fear T, Ahmed $H$ (2013) Digital rectal examination in prostate cancer screening. Univ West Ont Med J 82(1):10-11

12. Baade PD, Youlden DR, Cramb SM, Dunn J, Gardiner RA (2013) Epidemiology of prostate cancer in the Asia-Pacific region. Prostate Int 1(2):47-58

13. Cancel-Tassin G, Romana M, Gaffory C, Blanchet P, Cussnot O, Multigner $L$ (2015) Region 2 of $8 q 24$ associated with the risk of aggressive prostate cancer in Caribbean men of African descent from Guadeloupe (French West Indices). Asian J Androl 17(1):117-119

14. Jorge RA, Alvarez EC, Rodríguez ZC, de Moya Anegón F (2013) Intersectoral relationships, scientific output and national policies for research development: a case study on Cuba 2003-2007. Revista Cubana de Información en Ciencias de la Salud (ACIMED) 24(3):243-254

15. Oliveira MRFD, Gomes ADC, Toscano CM (2011) QUADAS and STARD: evaluating the quality of diagnostic accuracy studies. Rev Saude Publica 45:416-422

16. Schmidt L, Shokraneh F, Steinhausen K, Adams CE (2019) Introducing raptor: Revman parsing tool for reviewers. Syst Rev 8(1):151

17. Ahmed MEM, Higazi NZ, Abuidris DO, Idris AA, Khalid KE, Omran M, Algaili AM (2009) Prostate specific antigen versus digital rectal examination as screening for ca prostate in Sudanese patients. Sudan J Public Health 4(2):278-281

18. Walsh AL, Considine SW, Thomas AZ, Lynch TH, Manecksha RP (2014) Digital rectal examination in primary care is important for early detection of prostate cancer: a retrospective cohort analysis study. Br J Gen Pract 64(629):e783-e787

19. Issa MM, Zasada W, Ward K, Hall JA, Petros JA, Ritenour CWM, Goodman M, Kleinbaum D, Mandel J, Marshall FF (2006) The value of digital rectal examination as a predictor of prostate cancer diagnosis among United States Veterans referred for prostate biopsy. Cancer Detect Prev 30(3):269-275

20. Sunanda D, Das RK, Mukherjee S (2014) Role of prostate specific antigen, digital rectal examination and trans rectal ultrasonography in the diagnosis of prostate cancer in patients with lower urinary tract symptoms. Arch Clin Exp Surg (ACES) 3(1):40-46

21. Ojewola RW, Tijani KH, Jeje EA, Ogunjimi MA, Anunobi CC, Adesanya AO (2013) An evaluation of usefulness of prostate specific antigen and digital rectal examination in the diagnosis of prostate cancer in an unscreened population: experience in a Nigerian teaching hospital. West Afr J Med 32(1):8-13
22. Borkenhagen JF, Eastwood D, Kilari D, See WA, Van Wickle JD, Lawton CA, Hall WA (2019) Digital rectal examination remains a key prognostic tool for prostate cancer: a national cancer database review. J Natl Compr Canc Netw 17(7):829-837

23. Naji L, Randhawa H, Sohani Z, Dennis B, Lautenbach D, Kavanagh O, Bawor M, Banfield L, Profetto J (2018) Digital rectal examination for prostate cancer screening in primary care: a systematic review and metaanalysis. Ann Fam Med 16(2):149-154

24. Reis LO, Simão AFL, Baracat J, Denardi F, Gugliotta A (2013) Digital rectal examination standardization for inexperienced hands: teaching medical students. Adv Urol 2013:1-5

25. Mistry K, Greg C (2003) Meta-analysis of prostate-specific antigen and digital rectal examination as screening tests for prostate carcinoma. J Am Board Fam Med 16:95-101

26. Roobol MJ, Schröder FH (2014) The rate of over-diagnosis inextricably linked to prostate-specific antigen-based screening for prostate cancer can be quantified in several ways, but what is the practicable message? Eur Urol 65(6):1056-1057

27. Lange EM, Salinas CA, Zuhlke KA, Ray AM, Wang Y, Lu Y, Ho LA, Luo J, Cooney KA (2012) Early onset prostate cancer has a significant genetic component. Prostate 72(2):147-156

28. So WK, Choi KC, Tang WP, Lee PC, Shiu AT, Ho SS, Chan HY, Lam WW, Goggins WB, Chan CW (2014) Uptake of prostate cancer screening and associated factors among Chinese men aged 50 or more: a populationbased survey. Cancer Biol Med 11(1):56

29. Al-Rumaihi K, Al Jalham K, Younes N, Majzoub AA, Shokeir AA (2013) The role of an abnormal prostate-specific antigen level and an abnormal digital rectal examination in the diagnosis of prostate cancer: a crosssectional study in Qatar. Arab J Urol 11(4):355-360

30. Gosselaar C, Roobol MJ, Roemeling S, Schröder FH (2008) The role of the digital rectal examination in subsequent screening visits in the European randomized study of screening for prostate cancer (ERSPC), Rotterdam. Eur Urol 54(3):581-8

31. Abdrabo AA, Fadlalla Al, Fadl-Elmula IM (2011) Significance of serum total prostate specific antigen and digital rectal examination in the diagnosis of prostate cancer. Saudi Med J 32(11):1133-1136

\section{Submit your manuscript to a SpringerOpen ${ }^{\circ}$ journal and benefit from:}

- Convenient online submission

- Rigorous peer review

- Open access: articles freely available online

- High visibility within the field

- Retaining the copyright to your article

Submit your next manuscript at springeropen.com 